\title{
Adverse Drug Reactions and its Importance in Clinical Practice
}

Jannatul Ferdoush ${ }^{1 *}$

'Department of Pharmacology \& Therapeutics Army Medical College Chattogram Chattogram, Bangladesh.
*Correspondence to:

\section{Dr. Jannatul Ferdoush}

Associate Professor

Department of Pharmacology \& Therapeutics

Army Medical College Chattogram

Chattogram, Bangladesh.

Mobile : +8801856189977

E-mail: jannatfkh@yahoo.com

Date of Submission : 18.05 .2019

\section{"All Drugs are Dangerous, Some May Also be Useful",}

It would be better if we call them poison rather than medicine. We learned about the potentials of medicine of causing harm through thalidomide tragedy about 50 years ago. The letter to the Lancet by Dr. William McBride, Australian Obstetrician, in December 1961 observed this syndrome called phocomelia. That time 10000 babies were born with phocomelia as their mother had been exposed to thalidomide as morning sickness drug during a short period of their gestation. It was a terrible syndrome and that was the starting point. A lot of process around the world, improve regulations, improve attention of the safety of medicines and that lead to establishment of the WHO pharmacovigilance pilot program in 1968. Later on WHO established their collaborating center in UPSALA University and named as Upsala Monitoring Center ${ }^{2}$. We woke up then, we still need to keep wake because this terrible effects of medicines are happening every day to hundreds to thousands of people around the world. There is an expectation that medicine should be safe as because they have been tasted, registered by authorities. Each patient is unique and each treatment situation is unique. And what is the right drug treatment for one might be a bad choice for another. There is no one size fit for all here.

So, what do we normally do to find out the risk of medicine? First we try to find out the beneficial effect in animal models, and then move in to clinical trial. Preregistration clinical trial involves a few thousands of people with specific disease condition the length of the time of clinical trial exposure was short. So after registration, thousand to millions of patients are taking that particular medicine and getting exposure that demonstrate different kind of adverse effect which are less common. Moreover genetic, racial, environmental factor influence the pattern to a greater extent. Pregnant, children, elderly are carefully excluded from the trial. Another thing in clinical practice, people have many co-morbidities, they take all kinds of drugs including herbal medicine, clinical trials are so expansive, company does not want to spend extra day on them then they need to. We have no clues what is happening to them in long time exposure from clinical trial. So medicine are not safe as they are registered and being authorized for marketing.

We know half about beneficial and adverse effects of drug at the time of registration. That is more applicable for adverse effect because the study is conducted to maximize the benefits. So the remaining half of adverse effect we know after registration through adverse drug reaction reporting. And here is pharmacovigilance begins. Pharmacovigilance is defined by WHO, in $2002^{3}$. It states that the science and activities relating to the detection, assessment, understanding and prevent adverse effects or any other possible drug related problems.

So not only Adverse Drug Reactions (ADRs) like type A,B, C, D, E but also other drug related problem also included. The term pharmacovigilance has its own identity. It is not just only product and the safety of the products. It is concerned about how the product is being used according to recommendations and in fact this is 
the most common reason for hospitalization that are due to or related to medicine. Medication errors, dependence, abuse and poisoning are also included. The focus has shifted from drug safety to patient safety. It is the patient that we care about, we want to keep safe.

In developed country ADRs reporting and monitoring has become a routine practice concerning patient safety. But in Bangladesh the health professionals, patients/consumers are not adequately aware about ADRs. In USA approximately one in 7 hospital in patient experiences ADR and overall incidence of serious ADRs is $6.7 \%$ and fetal ADRs is $0.32 \%$ which translate to $1,06,000$ individual per year dying from ADRs. That puts ADR between $4^{\text {th }}$ leading causes of death ${ }^{4}$. In our country, very few ADRs were published in scientific journals. Among those, Islam and Rahman reported a case of fatal toxic epidermal necrolysis due to levofloxacin ${ }^{5}$. A study conducted in Dhaka Medical College Hospital revealed $11.9 \%$ of all outpatient department diagnosed as $\mathrm{ADRs}^{6}$. That percentage is appeared high in Bangabandhu Sheikh Mujib Medical University (BSMMU) wherein OPD 3.7\% and inpatient department 3.40\% are diagnosed as $\mathrm{ADRs}^{7}$. That was really shocking. It never used in any statistics about the highest cause of mortality. Because we talk about CVS disease, diabetes etc. This are happening silently everyday basis and we are not counting properly. $70 \%$ of this adverse effects are avoidable that means if we aware of that $70 \%$, if we use medicine correctly according to guideline and instructions that should not happened. The economic burden of ADRs 177.4 million dollars only in USA ${ }^{8}$. So we can easily assume what amount of economic burden that ADRs puts on the overall health care.

Till today, spontaneous reporting is the most common system of detecting ADRs. Many drugs were withdrawn from the market due to safety concern during post-marketing surveillance. In Bangladesh, WHO supported establishment of an Adverse Drug Reaction Monitoring Cell in Directorate General of Drug administration (DGDA) in 1996. But unfortunately in last 20 year, the DGDA authorities received only 50 ADRs reports 9 .
Inadequate knowledge and reluctant attitude of the doctors have been found to be associated with underreporting. There is no formal target teaching and training about detection and reporting of ADRs in the undergraduate curriculum. It contain ADR reporting and how to communicate risk benefit issue to patient but the mentioned content are not adequately taught and evaluated during undergraduate study and curriculum.

We just cannot stand there and see what is happening. Health care professional faced with patient on continuous basis and of course every patient is a challenge. If a doctor prescribes a medicine to patient and he returns few days later with symptoms and doctor suspect that it is due to ADR. Doctor usually change the medication and report to DGDA by using his digital device in a matter of minute. Other area doctor in home and abroad practicing and find same ADR and report. The DGDA send the report to the regulatory authority of Upsala Monitoring Center, WHO. Whole previous data including clinical trial and current reports are reviewed. Then the label of medicine will be updated, company may changes packaging the information of drugs and notify the doctor or the drug may be withdrawn from the market. So where there is suspicion of an undesirable medical events with drug it should be reported to pharmacovigilance center. No proof, no evidence needed.

It is our moral duty to warn if you know that something is harmful to another person. But unfortunately our physicians do not take the matter seriously and such negligence is detrimental to the patients. If something that threatens our family member or our neighbor we are more likely to warn or do something. But if the risk is happened to someone else around the globe that really makes no difference. So not reporting a serious unknown reaction is unethical. By creating awareness and by conducting training to our future prescribers about pharmacovigilance at undergraduate medical course and providing continuous medical education to the prescribers may improve the existing status of underreporting of ADRs and save many lives because of its consequence.

\section{REFERENCES}

1. Moore N. Assessing drug safety. BMJ. 2005;330: 539-540.

2. Upsala Monitoring Center (UMC) News, public services, 2014. Two south Asian countries join the WHO programme. Published ion $23^{\text {rd }}$ December 2014. Available at http:/www.who-umc.org/DynPage.aspx id=108464\&mnl =7347\&mn2=7489\&mn3=7248\&newsid=11704.

3. The importance of pharmacovigilance WHO, 2002.

4. Lazarou J, Pome Hanz BH, Corey PN. Incidence of adverse Drug Reactions in hospitalized patients: A metaanalysis of prospective studies. JAMA. 1998; 27:1200-1205.

5. Islam AFMS, Rahman MS. Levofloxacin induced fatal toxic epidermal necrolysis. Annals of Pharmacotherapy. 2005;37-39.

6. Begum ZA, Sultana S, Umah BU, Ferdous AH, Uddin MK, Islam SMH. Study of Adverse drug reactions in outpatient department of a teaching hospital. Bangladesh journal of pharmacol. 2012;104-107.

7. Akter M. Effect of educational intervention on detection and reporting of Adverse drug reactions in different level hospitals. MD. Thesis, BSMMU, Dhaka. 2015.

8. Ernst FR, Grizzle AJ. Drug-related morbidity and mortality: Updating the cost-of-illness model. J Am Pharm Assoc (Wash). 2000;41(2):192-199.

9. Uzzal M. Doctors fails to Report Adverse drug reactions. Dhaka Tribune. 2013; 1:16. 